\title{
MATERIALS WITH SHAPE MEMORY EFFECT FOR APPLICATIONS IN MARITIME
}

\author{
Špiro Ivošević* ${ }^{\oplus}$, Rebeka Rudolf**(i) \\ * University of Montenegro, Maritime Faculty Kotor, Dobrota 36 Str., 85330 Kotor, Montenegro; \\ e-mail: spiroi@ucg.ac.me; ORCID ID 0000-0001-6670-4770 \\ ** University of Maribor, Faculty of Mechanical Engineering, Smetanova 17 Str., 2000 Maribor, Slovenia; \\ e-mail: rebeka.rudolf@um.si; ORCID ID 0000-0003-0510-5752
}

\begin{abstract}
In this review it is presented the insight of challenges faced by all branches of industry in the new age, and especially the maritime industry, strive for sustainable development, better energy control, use of materials with functional properties such as shape memory, all in the direction of increasing safety and comfort. Therefore, the development of new materials with shape memory, which is associated with the introduction of optimized production and the achievement of better functional properties. This leads to new applications in different systems and possible use on devices, which meet the rigorous requirements of the modern industry.

The research into new materials with shape memory effect and their applied use in maritime is a challenge that many researchers have encountered in recent decades, and this is why in this paper we look at the basic engineering aspect of these materials and their current as well as future applications in the maritime industry. An overview of several innovations that testify shape memory effect and superelasticity in different maritime fields will be presented in this review.
\end{abstract}

\section{Keywords:}

shape memory materials, functional properties, maritime applications, innovation.

\section{Research article}

(C) 2019 Špiro Ivošević, Rebeka Rudolf This is an open access article licensed under the Creative Commons Attribution-NonCommercial-NoDerivatives 4.0 license (http://creativecommons.org/licenses/by-nc-nd/4.0/) 


\section{INTRODUCTION}

Since the discovery of shape memory effect (SME) long time ago in 1932 and to the present date, numerous research has been focused on research of different alloys that undergo thermoplastic martensite transformation [8]. These materials have ability to change their shape, position, stiffness, natural frequency and other mechanical characteristics when expand to temperature. A research of SME in different branches of industry brought to discovery other unique phenomena such as superelasticity (SE) and their ability for doing a work or damp vibration (high damping) [9]. Up to present date many alloys on the base of $(\mathrm{Ag}, \mathrm{Au}, \mathrm{Al}, \mathrm{Cu}, \ldots)$ were considered and the most significant are on the basis of $\mathrm{Cu}, \mathrm{Al}$ and $\mathrm{Ni}$ [15]. Materials on the basis of Ni-Ti with shape memory effects were applied during sixties and seventies of the last century in a production of different products in ships and submarines in the US Navy. Also they found application in aeronautics, rail road and maritime field, automotive, telecommunications, robotics. Medical industry uses these research in terms of wider applications of these alloys and research of their characteristics.

Review is organized through the three sections. In section 'Specific characteristics of shape memory alloys' we present basic technical aspect and effects of shape memory alloy (SMA), in section 'Review of SMA different maritime applications' we reviewed some SMA applications and innovation in maritime sectors. Concluding remarks and directions for future research and application of SMA in nautics are given in 'Conclusions'.

\section{SPECIFIC CHARACTERISTICS OF SHAPE MEMORY ALLOYS}

Shape memory alloy (SMA) are new smart materials with several specific thermo-mechanical properties which characterize their uniqueness and behaviour. These smart materials have two basic phase systems a higher temperature austentic phase and lower temperature martensitic phase [2]. These alloys are able to memorise and recover its original shape, after it has been deformed by heating over its transformation temperature. During the structural phase transformation from high temperature phase (called Austentite or Beta phase) to a low temperature phase (called Martensite), and during transformation the atomic lattice of the alloy undergoes a microscopic atomic shearing which is responsible for the macroscopic change of shape (fig. 1) [20]. This transformation between phase systems in the materials that was caused by stress or temperature is known shape memory effect. 

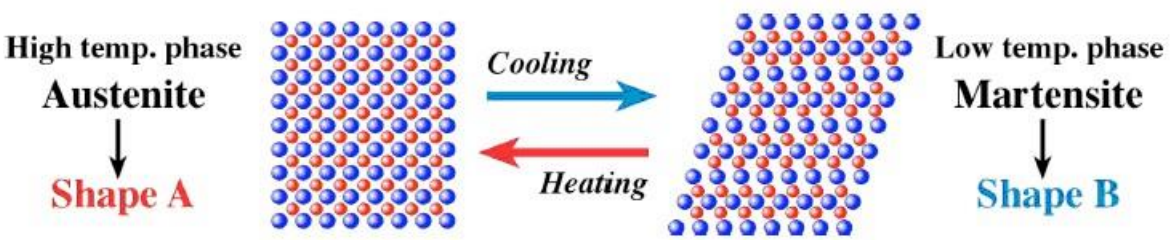

Fig. 1. Schematic presentation of the transformation in shape memory alloys [20]

This transformation can be completely reversible by cooling and heating and received the name of Thermoelastic Martensitic Transformation (TMT) [10, 29]. The martensitic transformation is one of the most pervasive phase transformations observed to occur in a number of material systems including metallic, polymeric and ceramic systems [4]. The material transforms from a greater crystallographic symmetry phase (austenite phase) to a lower symmetry martensite having multiple symmetry related variants [5]. Martensitic transformations can be thermoelastic or non-thermoelastic.

\section{Specific characteristic of SMA}

The key thermo-mechanical properties of shape memory alloy are: shape memory effect (SME), superelastic and pseudoelastic effect, high damping capacity and double shape memory effect. All of this thermo-mechanical properties are key of the powerful potential of these smart materials for their applications in different type of industry sector $[7,10,18,29]$.

\section{Shape memory effect}

The main attractive features of shape memory materials are the capabilities of maintaining a deformed shape up to heat induced recovery of the original shape (shape memory effect - SME). It describes the phenomenon where materials assume a particular shape upon deformation in the martensite phase but reverse their original shape (dimension) prior to deformation when subjected to temperatures above their transition temperature [14]. The material's reversibility is associated with temperature sensitive change (thermoelasticity) in martensite either its growth or shrinkage [30]. In the case of shape memory materials, the martensite shrinks to give up the strain energy stored in the material during martensite deformation when heated to certain temperatures above the transformation temperature [24]. This temperature driven crystallographic reversibility of the martensitic structure can also be attributed to low energy and loss of symmetry during martensitic transformation. 
The temperatures that define the transition from martensite to austenite (reverse) on heating differ from the temperatures that define the transition from austenite to martensite (forward) on cooling. This results in a delay in the transformation known as transformation temperature hysteresis, which can be usually between $10{ }^{\circ} \mathrm{C}$ and $50{ }^{\circ} \mathrm{C}$ depending on the alloy. It is defined as the difference between the temperatures at which $50 \%$ transformation to austenite occurs on heating and $50 \%$ transformation to martensite on cooling [27]. In addition the level and type of transformation hysteresis determines the functionality of shape memory material (its application) [26]. The transformation temperature hysteresis forms a loop (hysteresis loop) which is a macroscopic manifestation of the lag between the forward transformation and backward transformation as the material undergoes thermoelastic martensitic transformation [28].

\section{Pseudoelasticity or superelasticity}

Recovering the original shape after large deformations induced by mechanical load it is known as pseudoelasticity (PE). PE behaviour of SMMs is referred to as a reversible martensitic transformation, which is not due to change in temperature, but to the change in stress state. A sufficiently large load causes the transformation of austenite into martensite. Unloading returns the transformation of the austenite and the original shape. During loading-unloading, the material response shows a hysteretic cycle with; when the direct and inverse transformations take place, the stress remains mainly constant over a wide range of deformation respectively at the upper and lower plateau (wide plateau).

These materials have the ability to undergo extensive deformation when load is applied at specific temperatures and revert back to their original dimension when the load is removed [1]. During this transformation the material undergoes large elastic strain which is not a function of bond stretching but reversible motion of domain boundaries between the variants of martensite. The temperature at which the transformation starts has a direct relation to the magnitude of stress applied; higher stress magnitude implies higher transformation temperature [25].

\section{Damping capacity}

Damping capacity describes the ability of a material to absorb or suppress vibrational energy [31]. The mechanical damping of a material is as a result of irreversible transformation of mechanical energy dissipated into thermic energy. High 
damping capacity is desirable in most engineering materials and SMAs exhibit damping capacity higher than most materials [16]. This is attributed to high internal friction during martensitic transformation which imply that SMAs makes energy dissipation efficient in these materials. These mobile interfaces are; the interface between the austenite and martensite phase, the interface between the martensite variants and the interface of twin boundaries within the martensite [17]. The damping capacities of SMAs increases in the martensite phase due to the high density of martensite variants present and maximum when stress induced martensite is formed [13].

\section{Review of engineering aspects of SMAs applications}

Shape memory alloy with previously analysed effects make these alloys very favourable for various commercial applications that we may group in those based on free recovery, constrained recovery, actuators and superelasticity. These features of shape memory alloy may be viewed from an engineering as a possibility of using shape memory effect to generate motion and/or force, while superelasticity can store deformation energy. In that sense, shape memory events which can occur in combination of stress and strain perspective were shown on fig. 2 , in simple terms using the example of straight tensile wire which is fixed at the end.

Fig. 2a explains situation if stretching wire at room temperature generates an elongation after unloading. The wire remains in the stretched condition until it is heated above the transformation temperature of this particular alloy. It will then shrink to its original length as no load is applied, this is called free recovery. Subsequent cooling below the transformation temperature does not cause a macroscopic shape change [33].

If, after stretching at room temperature, the wire is prevented from returning to its original length, i.e. if constrained to the extended length upon heating above the transformation temperature, it can generate a considerable force. This so-called constrained recovery is the basis of many successful applications [32] and it is shown on fig. $2 \mathrm{~b}$. If the opposing force can be overcome by the shape memory wire, it will generate motion against a force, and thus do work. Upon beating, the wire will contract and lift a load, for instance. Upon cooling, the same load will stretch the now martensitic wire and reset the mechanism. This effect is called two-way-effect with external reset force is shown on fig. 2c [33]. 


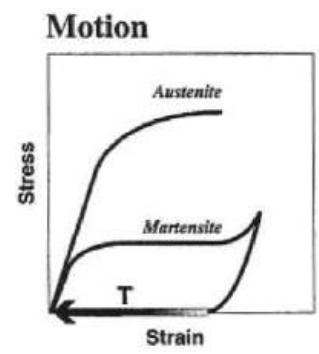

a

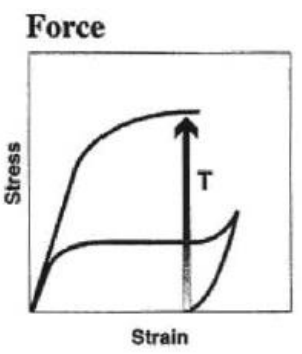

b

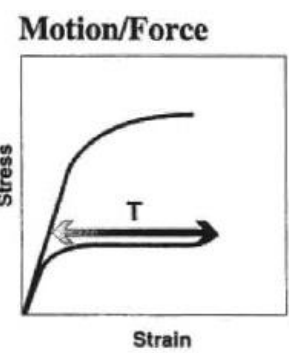

C

Fig. 2. Shape memory events in the stress/strain perspective [6]

In fig. 3 five commonly used scenarios are compared with regard to the force or displacement response. The level of the force in fig. 3a obviously is given by the weight of the 'dead load', while the slope of the force/displacement line in fig. $3 \mathrm{~b}$ represents the spring rate of the biasing steel spring. In fig. 3c two shape memory wires are working in opposing directions. When wire 1 is heated (e.g.by electrically heating), it contracts, moves an object, and simultaneously stretches wire 2 .

The object can be moved in the opposite direction by heating wire 2 after cooling of wire I. So-called reverse biasing is shown in fig. $3 \mathrm{~d}$ and e. The magnet causes the shape memory wire to generate a high static force that drops sharply when the magnet is separated from its holding plate. A slower drop in force can be achieved by using a cam arrangement with a decreasing lever during actuation of the shape memory wire. Reverse biasing is beneficial when rough cyclic stability is important [28].

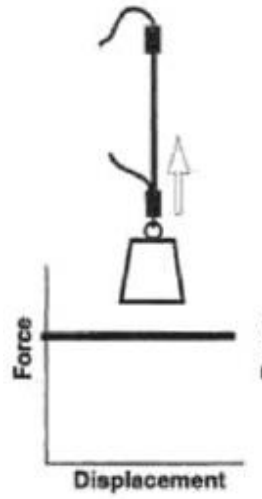

a

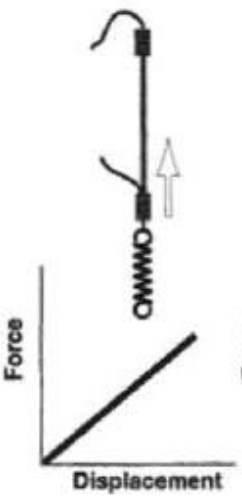

$\mathrm{b}$

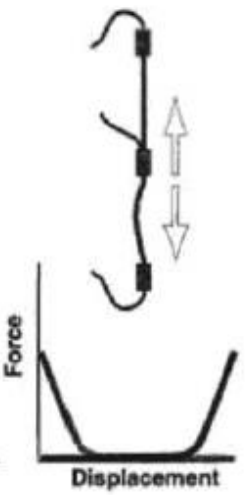

C

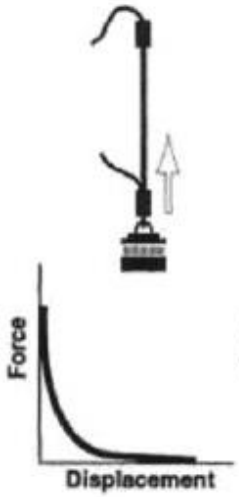

d

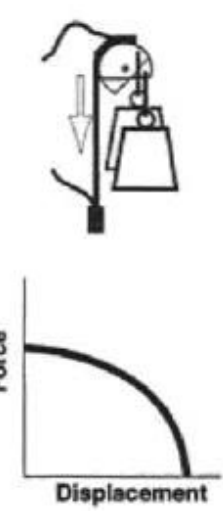

e

Fig. 3. Biasing Mechanisms and their effect on force/displacement characteristics [34] 
Under optimum conditions and no load the shape memory strain can be as high as $8 \%$, but for the cyclic applications strain is much less [11]. The same applies for the stress; for a one-Lime actuation the austenitic yield strength may be used as maximum stress. Much lower values have to be expected for cyclic applications [34].
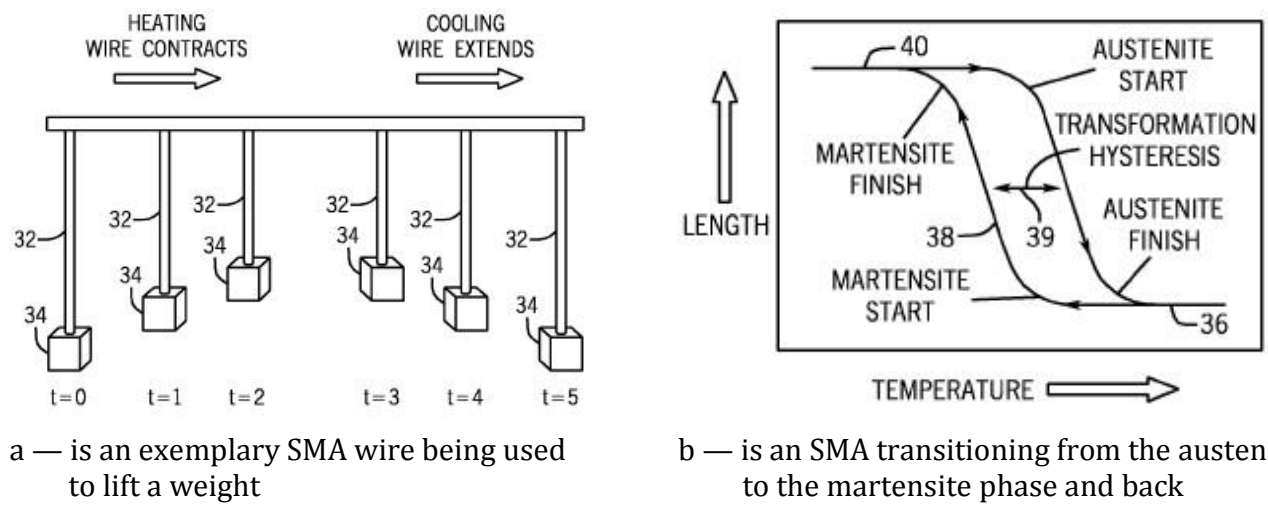

$\mathrm{b}$ - is an SMA transitioning from the austenite to the martensite phase and back

Fig. 4. Shape memory effect due to process of wire heating and cooling (a) and transformation hysteresis (b) SMA [23]

During the process of heating wire can lift weight and during the process of cooling left weight in predetermined position (fig. 4a). Process of transition from austenite to martensite can cause transformation hysteresis as it is shown in fig. $4 \mathrm{~b}$.

\section{REVIEW OF SMA DIFFERENT MARITIME APPLICATIONS}

Eyeglass frame and the antenna of mobile phone were widely used applications of SMAs. SMAs have been used in vibration dampers [37] and isolators [12] due to SMAs' high internal friction. For example, Aiken et al. (1993) have suggested using SMA as passive energy dissipater to increase the hysteresis damping in structure under earthquake [1]. The more advanced applications are in passive/active control system [3, 22], smart/adaptive structures [19,21], and composite structures [35]. Due to its excellent bio-compatibility, Nitinol has been used to make many medical instruments. For example, vascular stents [36] made by Nitinol wires can be woven into cylindrical shapes to reinforce blood vessels [15].

The most significant application of SMA up to date has been registered in aviation industry do, medicine, as well as other transportation branches such as automobile industry, rail etc.

$3(218) 2019$ 
In order to review different SMAs application in maritime industry in following paragraph some SMAs applications will be analysed.

In order to find adequate substitute for orbital welding in deep sea, new smart material can be used for connecting tube. Furthermore, variety of subsea equipment cam be subjected both to low and high temperature (different equipment such as valves and other flow control equipment's) can be under the elevated temperature while fluids flow through the equipment). This can lead to thermal stress, wear, degradation, overheating so it is necessary to maintain temperatures within an acceptable range.

Also SMA can be used for SMA thermostat and transfer thermal energy in electricity under the power plant which will be explained in future paragraph.

\section{Subsea tube devices}

Shape memory alloy has been used as a connection for tubes for coupling or junction in subsea environments, substituting the orbital welding process which is commonly used [9]. Namely, Subsea Christmas trees which are used in oil gas fields have various tube connectors in order to avoid leakage on connecting line. The connection of hydraulic tubes usually uses orbital welding process which lead to few problems during this process, including e. g. a special preparation of the tubes, use of specific machines to be employed for orbital welding, qualified staff, a complex welding procedure, post-welding preparation, visual inspection of $\mathrm{X}$ rays including the whole preparation process, a wide workspace and a huge time to perform the operation, among others [9].

In order to reduce problems of orbital welding and find a new solution for submerse tube coupling, shape memory alloy provides advantages such as: the tension of the connection is not affected by vibrations or impacts; the assembling time is insignificant in comparison with orbital welding, since it requires just a few minutes; increase in work safety; work with $\mathrm{X}$ ray inspection is dismissed; no requirement of highly qualified staff and training staff service and reduction of about $1 / 3$ in the total cost of the operation. Also, working temperature for the connection of the invention will depend on the kind of isolating material, and depending on the used material work temperature should be between $0{ }^{\circ} \mathrm{C}$ and $60^{\circ} \mathrm{C}$ for 25 years under subsea environment [9].

According to the above drawings, in subsea tubing (4), a sleeve connection of a shaped memory alloy material (1) is provided. SMA is originally manufactured with its internal diameter (D1) shorter than the external diameter (D4) of said tubing (4). Said sleeve connection made of a shaped memory alloy material (1) internally has 
a covering material made of a dielectric material (2) and, more internally, a sleeve or layer (3) of an anti-corrosive material. That anticorrosive material is a nickel-chrome material with the addition of molybdenum and niobium. Said layer (3) made of an anti-corrosive material is installed next to the external face of said tubing (4) and internally has protruding portions (5) designed to grasp the external surface of the tubing (4), forming streaks (6) [9]. In fig. 5 we can see different view of cross-sections and perspective of tube.

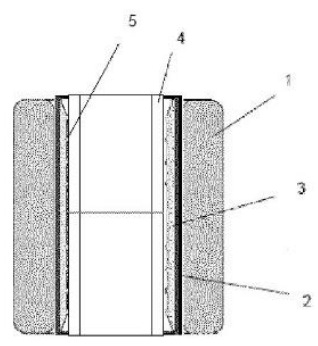

a

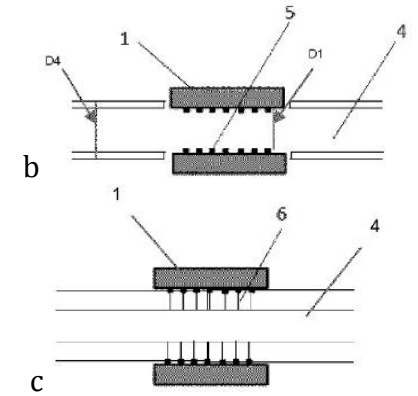

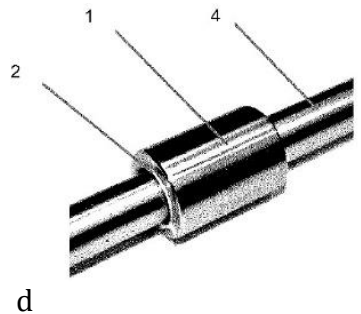

d

Fig. 5: a - lengthwise cut view of the connection as coupled to the tubing of the invention; $\mathrm{b}-$ view of the connection showing its internal diameter shorter than the external diameter of the tubing; c - view of the connection and respective tubing showing the expanded state; $\mathrm{d}$ - perspective view of a connection and respective tubing assembled according to an embodiment the invention [9]

\section{Shape memory alloy thermostat for subsea e qui p m e $\mathbf{n}$}

As it is mentioned, one of certain embodiments, which can include smart material is SMA thermostat. The SMA thermostat includes a body, a sleeve, a biasing spring and an SMA spring. Upon actuation of the SMA spring at a phase transition temperature, the sleeve is configured to shift and exposes flow ports formed in the body.

The SMA thermostat has one or more SMA springs which are designed and manufactured to undergo a phase transition at a specified temperature (e.g., a temperature below or overheat from elevated temperatures). SMA spring of the SMA thermostat are exposed to the sea water within the insulated structure which is on different temperature of surrounding water. When the seawater in the insulated structure reaches the specified temperature, it actuates a sleeve of the SMA thermostat. Later, the SMA spring compresses a biasing spring and opens one or more exit ports to create a flow passage between the interior of the insulated structure and the seawater environment. In other embodiments, the SMA spring may have a tension configuration. In other words, when the SMA spring undergoes the phase 
transition and actuates the sleeve of the SMA thermostat, the SMA spring pulls the biasing spring, thereby creating tension in the biasing spring. When the exit ports are open, heated seawater within the insulated structure and the cold sea water surrounding the insulated structure cause the heated sea water to escape the insulated structure. In other words, the heated sea water flows to the lower temperature environment. Furthermore, the insulated structure allowing cold sea water to enter in the insulated structure and reduce the temperature inside of SMA thermostat. For example, absent any temperature regulation in the insulated structure 12 , the interior sea water 68 on SMA thermostat which is shown in figure may reach temperatures of approximately $30^{\circ} \mathrm{C}-140{ }^{\circ} \mathrm{C}, 40{ }^{\circ} \mathrm{C}-130{ }^{\circ} \mathrm{C}, 50{ }^{\circ} \mathrm{C}-120^{\circ} \mathrm{C}$, $60{ }^{\circ} \mathrm{C}-110^{\circ} \mathrm{C}$, or more [23].

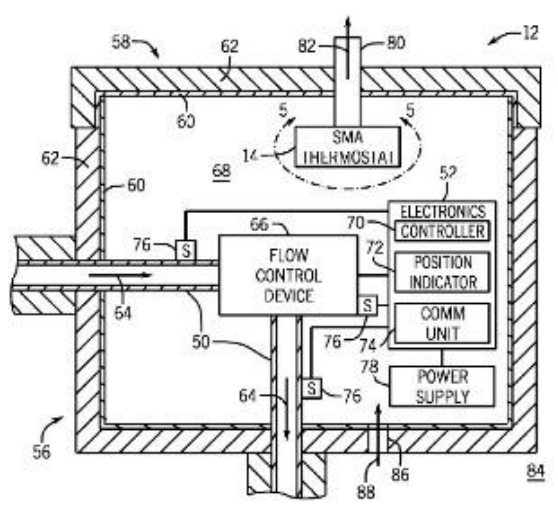

a

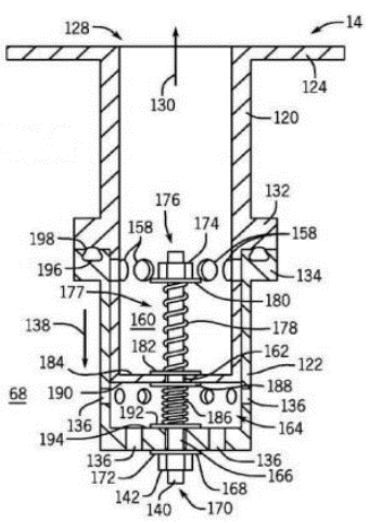

C

Fig. 6: a - is an embodiment of a subsea insulated structure having an SMA thermostat; $\mathrm{b}$ - is a perspective view of an embodiment of an SMA thermostat; $\mathrm{c}-$ is a cross-sectional side view of an embodiment of the SMA thermostat of $b$, taken along line 6-6 of $b$, illustrating the SMA thermostat in a closed position; $\mathrm{d}-$ is a cross-sectional side view of an embodiment of the SMA thermostat of figure $6 \mathrm{~b}$, taken along line $6-6$ of figure $6 \mathrm{~b}$, illustrating the SMA thermostat in an open position [23] 
The unique properties of SMAs make them more useful for thermostats comparing to electrical thermostats, due to fact that they operate without electrical sensors or equipment. In addition, SMA may be fabricated into different shapes, such as wires and thin films (SMA wires with diameters less than approximately $0.5 \mathrm{~mm}-1.0 \mathrm{~mm}$, $0.6 \mathrm{~mm}-0.9 \mathrm{~mm}$, or $0.7 \mathrm{~mm}-0.8 \mathrm{~mm}$ ) which can be used to form springs for use in the SMA thermostats (fig. 6) [23].

Even any kind of SMA can be used for SMA thermostat, one particular shape memory material which is characterized by long fatigue life and high corrosion resistance is called Nitinol, makes alloy of nickel and titanium. This allow is capable of up to approximately 5\% strain recovery or approximately $500 \mathrm{MPa}$ restoration stress with many cycles, depending upon the material composition. Furthermore, the composition of Nitinol (the amount of nickel or titanium in Nitinol) may be adjusted to achieve a desired transition temperature and adjusted to raise or lower the transition temperature [23].

\section{Shape memory alloydriven power plant}

A power plant configured for converting thermal energy to electricity includes a source of thermal energy provided by a temperature difference between a primary fluid having a first temperature and a secondary fluid having a second temperature that is different from the first temperature. In order to enhancing the temperature difference between the primary and secondary fluids the plant includes a collector, and a heat engine configured for converting at least some thermal energy to mechanical energy. The heat engine includes a pseudo plastically pre-strained shape-memory alloy disposed in heat exchange relationship with each of the primary and secondary fluids. Further, the plant includes a generator driven by the heat engine and configured for converting mechanical energy to electricity. A method of utilizing a naturally-occurring temperature difference between air and/or water to change a crystallographic phase of the shape memory alloy to convert the temperature difference into mechanical energy is disclosed.

Traditional electrical power plants often include a generator (driven by a water wheel, a diesel engine, or a steam turbine) which can convert one form of energy to electricity. In order to offer new solution for producing electricity SMA driven power plant can be used. This power plant are working on the base of energy conversion thermal energy to electricity. This method of converting a temperature difference into mechanical energy may be land-based or sea-based and may harvest naturally-occurring thermal energy. 
In fig. 7 we can see schematic presentation of power plant and schematic perspective view of generator and the heat engine.

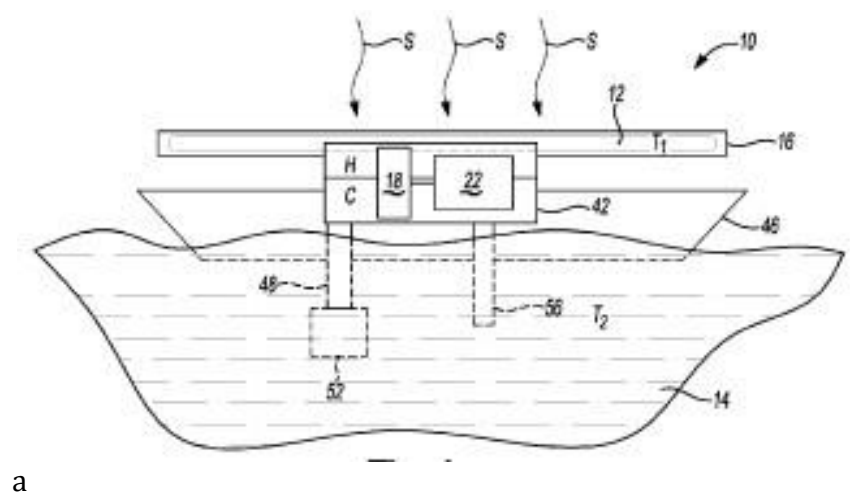

a

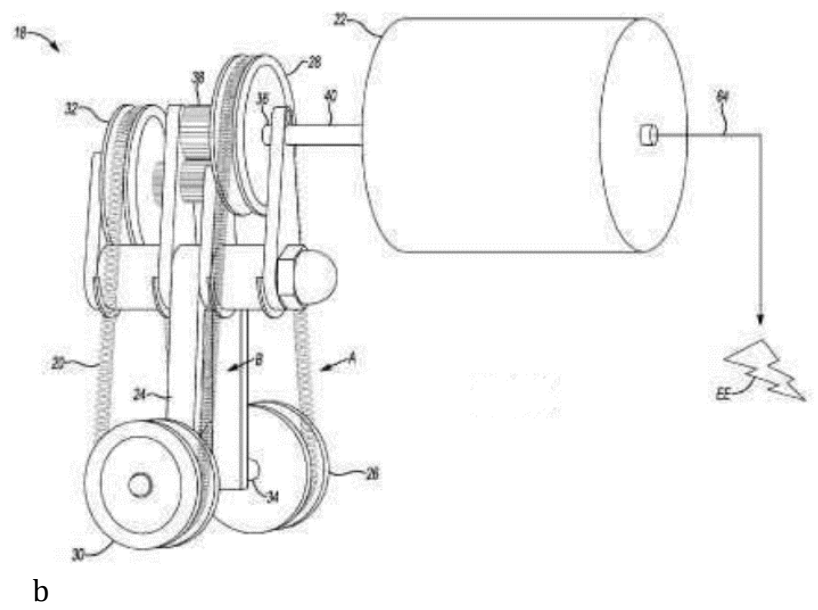

Fig. 7: a - is a schematic diagram of a power plant buoyantly disposed in a fluid and including a collector, a heat engine, and a generator driven by the heat engine; $b$ - is a schematic perspective view of the generator and the heat engine for combination within the power plant in fig. 7a [38]

As it is shown in fig. 7a, the power plant 10 includes a source of thermal energy provided by a temperature difference, between a primary and secondary fluid which are on different temperature. The primary fluid (item 12 in fig. 7a) and the secondary fluid (item 14 in fig. 7a) may each be selected from the group of gases, liquids, fluidized beds of Solids, and combinations thereof. For the power plant 10, the temperature difference $\Delta T$ may be less than or equal to about $300{ }^{\circ} \mathrm{C}$. For example, the temperature difference $\Delta T$ between the first temperature $T$ and the second temperature $T$ may be as little as about $5^{\circ} \mathrm{C}$ and no more than about $100{ }^{\circ} \mathrm{C}$ or may be greater than or equal to about $5{ }^{\circ} \mathrm{C}$ and less than or equal to about $30{ }^{\circ} \mathrm{C}$, e.g., less 
than or equal to about $10{ }^{\circ} \mathrm{C}$. The power plant 10 has excellent efficiency and converts a maximum amount of thermal energy to mechanical energy and/or electricity EE, even at a temperature difference $\Delta T$ of less than or equal to about $10^{\circ} \mathrm{C}$, for example. And, as the temperature difference $\Delta T$ increases, the power plant 10 responds more energetically [38].

Referring now to fig. 7a, the power plant 10 includes a heat engine 18 which is configured for converting thermal energy, e.g., heat, to mechanical energy. The heat engine 18 includes a pseudoplastically pre-strained shape-memory alloy 20 (fig. 7b) having a crystallographic phase changeable between austenite and martensite in response to the temperature difference $\Delta T$ between the primary fluid 12 and the secondary fluid 14 (fig. 7). The shape-memory alloy 20 may be characterized by a cold state (when a temperature of the shape memory alloy 20 is below the martensite finish temperature $\mathrm{M}$, of the shape-memory alloy 20) or hot state (when the temperature of the shape-memory alloy 20 is above the austenite finish temperature $A$, of the shape memory alloy 20) [38].

In operation, when exposed to the temperature difference $\Delta T$ between the primary and secondary fluid, the shape-memory alloy 20 can change dimension upon changing crystallographic phase to thereby convert thermal energy to mechanical energy. Due to temperature differences SMA can change crystallographic phase from martensite to austenite and vice versa. Changes to crystallographic phase from martensite to austenite and thereby dimensionally contract if pseudo plastically pre-strained or from austenite to martensite and thereby dimensionally expand if under tensile stress so as to be ready to convert thermal energy to mechanical energy.

Shape memory alloy can be binary, trinary or any SMA exhibit a shape memory effect. Even shape memory alloy may have any suitable form as springs, tapes, wires, bands, continuous loops and/or combinations thereof in power plant invention in fig. 7a shape memory alloy may be formed as a continuous loop spring (item 20 in fig. 7b) [38].

Power plant 10 in fig. 7a also include generator 22 which is configured for converting mechanical energy to electricity. This generator is driven by heat engine 18, and mechanical energy resulting from conversion of thermal energy by shape memory alloy 20. In variation shown in fig. $7 \mathrm{~b}$ heat engine 18 may include lot of elements as frame 24 , wheels or pulleys $26,28,30,32$, gear sets 38 , drive shaft 40 axles 34, 36, and at. As the wheels or pulleys $26,28,30,32$ turn or rotate about the respective axles 34,36 of the heat engine 18 in response to the dimensionally expanding and contracting shape memory alloy 20 , the drive shaft 40 rotates and drives the generator 22 . At the final stage, the generator 22 mechanical energy converted to electricity [38]. 


\section{CONCLUSIONS}

In this review the functional properties of shape memory materials were explained in conjunction with the engineering use and known aspects in maritime. It was shown that possible applications of shape memory materials could be as a tube connectors, thermostat and continuous loop spring as a part of heat engine in power plant, which can assist in way to find some shape memory applications in nautical vessels. From this review it can be concluded that although connecting tube and shape memory thermostat can find a lot of applications in any marine sector (as shown in parts 'Subsea tube devices' and 'Shape memory alloy thermostat for subsea equipment') for power plant. This can be useful application in maritime industry due to operation on the sea surface and temperature difference of sea-water and hot atmosphere when they operate during nautical season.

\section{Acknowledgments}

This paper is a result of the initial phase of the research of different aspects of the sea and atmosphere to the production and application of smart materials of shape memory alloy in nautical industry. Project PROCHA - SMA is a part of EUREKA project which is jointly realized by Faculty of Stomatology in Belgrade, Zlatarna Celje and Faculty of Maritime Studies Kotor, University of Montenegro.

This research was funded by the BILATERAL PROJECT Slovenia - Montenegro and EUREKA PROGRAM PROCHA — SMA of Ministry of Science of the Republic of Montenegro.

\section{REFERENCES}

[1] Alaneme K. K., Okotete E. A., Reconciling viability and cost-effective shape memory alloy options - a review of copper and iron based shape memory metallic systems, 'Engineering Science and Technology, an International Journal', 2016, 19, pp. 1582-1592.

[2] Ameendraraj S., Fatigue behaviour of copper zinc aluminum shape memory alloys, Master thesis, University of Manitoba, 1998.

[3] Baz A., Ro J., Mutua M., Gilheany J., Active Buckling Control of Nitinol-Reinforced Composite Beams, ADPA/AIAA/ASME/SPIE Conference on Active Materials and Adaptive Structures-Session 1992, 10, pp. 167-176.

[4] Bhattacharya K., Conti S., Zanzotto G., Zimmer J., Crystal symmetry and the reversibility of martensitic transformations, 'Nature', 2004, 428, pp. 55-59.

[5] Dasgupta R., A look into cu-based shape memory alloys: present scenario and future prospects, 'Journal Material Research', 2014, 29 (16), pp. 1681-1698. 
[6] Duerig T. W., Melton K. N., Proc. of SMA '86, Guilin 1986, 397.

[7] Duerig T. W., Melton K. N., Stoeckel D., Wayman C. M., Engineering aspects of Shape Memory Alloys, Butterworth — Heinemann, London 1990.

[8] Dye T. E., An Experimental Investigation of the Behavior of Nitinol, Master thesis, Department of Mechanical Engineering, Virginia Polytechnic Institute and State University, 1990.

[9] European Patent Application, EP 3290768 A1, Published in accordance with Art. 153(4) EPC, 2016.

[10] Funakubo H., Shape Memory Alloys, Gordon and Breach, London 1984.

[11] Gilbenson R. G., Working With Shape Memory Wires, Mondotronics, 1991.

[12] Graesser E. J., Cozzarelli F. A., Shape Memory Alloys as New Materials for Aseimic Isolation, 'Journal of Engineering Mechanics', 1992, 117 (11), pp. 2590-2608.

[13] Gupta P. K., Seena P., Rai R. N., Studies on shape memory alloys - a review, 'International Journal Advance Engineering', 2012, 3 (1), pp. 378-382.

[14] Hodgson D. E., Shape memory applications, 'Shape Memory Alloys', 1990, Vol. 2: Properties and Selection: Nonferrous Alloys and Special-Purpose Materials, ASM Handbook Committee, pp. 897-902.

[15] Huang W., Shape Memory Alloys and their Application to Actuators for Deployable Structures, $\mathrm{PhD}$ thesis, University of Cambridge, Department of Engineering, 1998.

[16] Humbeeck J. van, Damping properties of shape memory alloys during phase trans-formation, 'Journal Physic IV', 1996, 06 (C8), pp. C8-371-C8-380.

[17] Humbeeck J. van, Kustov S., Active and passive damping of noise and vibrations through shape memory alloys: applications and mechanisms, 'Smart Material Structure', 2005, 14 (5), pp. S171-S181.

[18] Humbeeck J. van, Shape Memory Alloys: A Material and a Technology, 'Advanced Engineering Materials', 2001, 3, pp. 837-850.

[19] Jia J., Rogers C. A., Formulation of a Laminated Shell Theory Incorporating Embedded Distributed Actuators, 'Journal of Mechanical Design', 1990, 112, pp. 596-604.

[20] Juan J. S., Applications of Shape Memory Alloys to the Transport Industry, International Congress on Innovative Solutions for the Advancement of the Transport Industry, San Sebastian, October 2006.

[21] Kakizawa T., Ohno S., Utilization of Shape Memory Alloy as a Sensing Material for Smart Structures, in Advanced Composite Materials in Bridges and Structures, 1996, pp. 67-74.

[22] Kim S., Passive Control Techniques in Earthquake Engineering, Proceedings of the SPIE, 1995, 2445, pp. 214-224.

[23] Kocurek C., Green C., Patent Application Publication, US 2013/0015376 A1, United States, 2013.

[24] Kubenova M., Processing and martensitic transformations of NiTi based alloys, PhD thesis, Brno University of Technology, 2014.

[25] Kumar P. K., Lagoudas D. C., Introduction to shape memory alloys, [in:] Shape Memory Alloys. Modelling and Engineering Applications, 2008, pp. 1-51. 
[26] Liu Y., Some factors affecting the transformation hysteresis in shape memory alloys, [in:] Shape Memory Alloys, ed. H. R. Chen, Nova Science Publishers Inc., 2010, pp. 361-369.

[27] Nemat-Nasser S., Guo W. G., Superelastic and cyclic response of NiTi SMA at various strain rates and temperatures, 'Mech. Mater.', 2006, 38, pp. 463-474.

[28] Ortin J., Dealey L., Hysteresis in shape memory alloys, 'International Journal Non-Linear Mechanic', 2002, 37, pp. 1275-1281.

[29] Otsuka K., Wayman C. M., Shape Memory Materials, Cambridge University Press, Cambridge 1998.

[30] Perkins J., Muesing W. E., Martensitic transformations cycling effect on Cu-Zn-Al shape memory alloys, 'Metall. Trans. A', 1983, 14 (1), pp. 33-36.

[31] Prasad D. S., Shoba C., Varma K. R., Damping behavior of commonly used reinforcement powders - an experimental approach, 'International Journal Engineering Science Technology', 2015, 18, pp. 674-679.

[32] Proft J. L., Duerig T. W., Engineering Aspects of Shape Memory Alloys, Butterworth-Heinemann, London 1990.

[33] Stoeckel D., Shape-memory alloys prompt new actuator designs, 'Advanced Materials and Processes', 1990, 138, pp. 33-38.

[34] Stoeckel D., The Shape Memory Effect - Phenomenon, Alloys and Applications, 'Proceedings: Shape Memory Alloys for Power Systems EPRI', 1995, pp. 1-13.

[35] Sun G., Sun C. T., One-Dimensional Constitutive Relation for Shape-Memory Alloy-Reinforced Composite Lamina, 'Journal of Materials Science', 1993, 28, pp. 6323-6328.

[36] Whitcher F. D., Simulation of in Vivo Loading Conditions of Nitinol Vascular Stent Structures, 'Computers \& Structures', 1997, 64 (5/6), pp. 1005-1011.

[37] Witting P. R., Cozzarelli F. A., Shape Memory Structural Dampers: Material Properties, Design and Seismic Testing, Technical Report NCEER-92-0013, 1992.

[38] Wittorf M., Browne A., Johnson N., Brown J. H., Patent Application Publication, US008299637B2, United States, 2012.

\section{MATERIAŁY Z PAMIECIAZ KSZTAŁTU DOZASTOSOWAŃ MORSKICH}

\section{STRESZCZENIE}

W artykule przedstawiono badania prowadzone nad nowymi materiałami z pamięcią kształtu. Opisano podstawowe aspekty inżynieryjne tych materiałów, ich właściwości funkcjonalne oraz przyszłe wykorzystanie w obszarze morskim. Dokonano przeglądu niektórych zastosowań materiałów z efektem shape memory alloy (SMA), pokazując ich innowacyjne rozwiązania. Opracowanie 
optymalnego procesu technologicznego do produkcji materiałów SMA i transfer wiedzy na poziomie przemysłowym stworzy nowe perspektywy dla żeglugi morskiej.

\section{Słowa kluczowe:}

materiały z pamięcią kształtu, właściwości funkcjonalne, zastosowania morskie, innowacje.

Article history

Received: 27.08.2019

Reviewed: 28.09.2019

Revised: $\quad 30.09 .2019$

Accepted: $\quad 30.09 .2019$ 